\title{
Study on $\mathrm{SO}_{3}$ emission test of typical ultra-low emission coal-fired units in western region of Inner Mongolia
}

\author{
Meng Wang, Zhiyong Zhang ${ }^{*}$, Suhua Hao, Yu Wu, and Zhiqiang He \\ Inner Mongolia Electric Power Science \& Research Institute, 010020 Hohhot, China
}

\begin{abstract}
To study the effect of types of boilers, pollutant treatment facilities and coal quality on $\mathrm{SO}_{3}$, emission concentration of $\mathrm{SO}_{3}$ was tested by controlled condensation method for seven typical ultra-low emissions coal-fired units in western region of Inner Mongolia. The test results showed that the $\mathrm{SO}_{3}$ emission concentration of all units ranged from $0.36 \mathrm{mg} / \mathrm{m}^{3}$ to $2.04 \mathrm{mg} / \mathrm{m}^{3}$, much lower than $5 \mathrm{mg} / \mathrm{m}^{3}$, so there was no need to add $\mathrm{SO}_{3}$ removal facilities. For the units burning the coal of same sulfur content, which adopt LLTESP and WESP has the lower $\mathrm{SO}_{3}$ emission concentration. The $\mathrm{SO}_{3}$ emission concentration can also be controlled at a lower value when SNCR and double-tower double-cycle WFGD technology are adopted in the unit burning medium-high sulfur coal.
\end{abstract}

Keywords: Ultra-low emission; $\mathrm{SO}_{3}$; Emission concentration; Controlled condensation method.

\section{Introduction}

Since 2014, China has vigorously promoted the transformation of coal-fired power plants to achieve ultra-low emission standard. By the end of 2019, the installed capacity of coal-fired power plants had reached ultra-low emission levels of about 890 million $\mathrm{kW}$ (about $86 \%$ of the total installed coal-fired power plants). Compared with 2014, the emmisions of particle matter, $\mathrm{SO}_{2}$ and $\mathrm{NO}_{\mathrm{X}}$ fell $82 \%, 86 \%$ and $84 \%$. The rapid improvement of the clean production level of the thermal power industry has made important contributions to the improvement of environmental quality [1].

Under the conventional pollutants (particle matter, $\mathrm{SO}_{2}, \mathrm{NO}_{\mathrm{X}}$ ) effective control, local governments gradually began to pay attention to the problem of "colored plume". On January 29, 2016, Shanghai environmental protection agency and Shanghai bureau of quality and technical supervision jointly issued DB 31/963-2016 "Air Pollutant Emission Standards for Coal-fired Power Plants", which is the first local standard in China to put forward requirements for the management of "colored plume". The standard points out that coal-fired power boilers should be taken the flue gas temperature control and other effective measures to eliminate the phenomena of "gypsum rain" and "colored plume". Since then, Tianjin, Shanxi, Guangdong, Jiangxi, Hebei, Zhejiang, Shaanxi and other provinces have

* Corresponding author: zyzhang1980@126.com 
issued standards, notices and plans to control the "colored plume" or "whitening". However, most of these policies or standards only require measures to control the "colored plume" and other phenomena, but do not set limits for pollutant emissions. In fact, after the ultralow emission transformation of coal-fired power plants, the ubiquitous "white plume" is formed by the condensation of gaseous water in flue gas injection into the atmosphere, which itself has little impact on the environment. However, the "blue plume" caused by the high $\mathrm{SO}_{3}$ emission concentration has a great impact on the environment and needs to be treated [2]. In addition, on October 11, 2019, the Ministry of Ecology and Environment of P.R.C issued "Action Plan for 2019-2020 Autumn and Winter Comprehensive Control of Air Pollution in the Beijing-Tianjin-Hebei Region and its Neighboring Regions". According to the plan, power plants that consistently meet ultra-low emissions requirements will not be compulsively required to deal with "white plume".

At present, China has not put forward specific requirements for $\mathrm{SO}_{3}$ emission of power plants. Twenty-two states in the United States have set emission limits for $\mathrm{SO}_{3}$ in flue gas from coal-fired power plants, and 14 of them have emission limits of less than $6 \mathrm{mg} / \mathrm{m}^{3}$. The emission limit of $\mathrm{SO}_{3}$ in Germany and Singapore is $10 \mathrm{mg} / \mathrm{m}^{3}$, while in Japan, $\mathrm{SO}_{3} / \mathrm{H}_{2} \mathrm{SO}_{4}$ is included in the limit of particulate matter for control. Only a few cities in China have set $\mathrm{SO}_{3}$ emission limits, such as Hangzhou, Hengshui and other cities require that $\mathrm{SO}_{3}$ in the flue gas emissions should not be higher than $5 \mathrm{mg} / \mathrm{m}^{3}$.

In order to evaluate $\mathrm{SO}_{3}$ emission behaviour of coal-fired power plants, this paper selected seven ultra-low emission coal-fired units in the western region of Inner Mongolia to research, and each unit adopts different types of boilers, pollutant treatment facilities and coal quality. The controlled condensation method is used to test the $\mathrm{SO}_{3}$ emission concentration, and the influence of pollutant treatment facilities and coal quality on $\mathrm{SO}_{3}$ emission are analyzed.

\section{Test case overview}

In this paper, seven units in the western region of Inner Mongolia were selected to test $\mathrm{SO}_{3}$ emission concentration. All units have completed ultra-low emission transformation. The boiler type, capacity and pollutant treatment facilities of the units are shown in Table 1.

Table 1. Basic information of test cases.

\begin{tabular}{|c|c|c|c|}
\hline Unit & Boiler & Capacity/MW & Pollutant treatment facilities \\
\hline Unit A & Pulverized coal fired boiler & 330 & LNC + SCR + EFF + WFGD \\
\hline Unit B & Pulverized coal fired boiler & 330 & LNC + SCR + ESP + WFGD \\
\hline Unit C & Pulverized coal fired boiler & 330 & LNC + SCR + ESP + WFGD \\
\hline Unit D & Pulverized coal fired boiler & 200 & LNC + SCR + EFF + WFGD \\
\hline Unit E & $\begin{array}{c}\text { Circulating fluidized bed } \\
\text { boiler }\end{array}$ & 350 & $\begin{array}{c}\text { SNCR + ESP + double-tower } \\
\text { double-cycle WFGD }\end{array}$ \\
\hline Unit F & Pulverized coal fired boiler & 300 & $\begin{array}{c}\text { LNC + SCR + LLTESP + WFGD } \\
+ \text { WESP }\end{array}$ \\
\hline Unit G & $\begin{array}{c}\text { Circulating fluidized bed } \\
\text { boiler }\end{array}$ & 350 & SNCR + FF + WFGD \\
\hline
\end{tabular}

The power plants (units) selected in this study adopt different types of boilers and pollutant treatment facilities. Boilers have pulverized coal fired boiler (PCFB) and circulating fluidized bed boiler (CFBB). Pollutant treatment facilities have low-nitrogen combustion (LNC) + selective catalytic reduction denitration (SCR) + electrostatic-fabric filters (EFF) + wet limestone-gypsum flue gas desulfurization (WFGD), LNC + SCR + electrostatic precipitation (ESP) + WFGD, selective non-catalytic reduction denitration $(\mathrm{SNCR})+\mathrm{ESP}+$ double-tower double-cycle WFGD, LNC + SCR + low-low temperature electrostatic precipitation (LLTESP) + WFGD + wet electrostatic precipitation (WESP), 
SNCR + fabric filters (FF)+ WFGD. These technology routes basic cover most of the ultra low emission control technology of coal-fired power plants on the market, with strong representation.

\section{Test methods and conditions}

\subsection{Test methods}

Test methods used for detecting $\mathrm{SO}_{3}$ of coal-fired power plants commonly are the controlled condensation method and the isopropanol absorption method, and the former is the most widely used $[3,4]$.

The literatures show that the results of tested by isopropanol absorption method are higher than those of by controlled condensation method, and the former is usually several times of the latter. The reason is that commercially available isopropanol often contains oxidizing impurities of peroxide, which leads to that $\mathrm{SO}_{2}$ can be catalytically oxidized to $\mathrm{SO}_{3}$, resulting in high test results. Therefore, all cases in this paper were tested by the controlled condensation method with the APEX XC-5000 $\mathrm{SO}_{3}$ tested instrument, and the standard of DL/T 1990-2019 was implemented.

The sampling and analytical method is as follows: the flue gas is extracted with a heated sampling gun (the temperature is controlled at $260^{\circ} \mathrm{C}$ ), and the coarse particulate matter is filtered by a heated filter of $200^{\circ} \mathrm{C}$. The $\mathrm{SO}_{3}$ is condensed into sulfuric acid mist by control condenser tube (serpentine tube) and collected under the action of inertial collision, which that the of the water bath temperature of the control condenser tube is controlled at $50 \sim 90^{\circ} \mathrm{C}$.

After sampling, the condenser tube is rinsed with $80 \%$ isopropanol solution, and the rinse solution is collected. Using barium perchlorate-thorium reagent to titrate and analyse $\mathrm{SO}_{4}{ }^{2-}$ concentration in rinse solution, and the $\mathrm{SO}_{3}$ concentration in the flue gas was calculated by combining the sampling volume. Fig. 1 shows the color changes of the sample during the titration process in the laboratory. Among a stands for the colorless rinse solution collected after sampling, $b$ stands for the saffron yellow solution with the addition of thorium reagent indicator, and c stands for the pink solution after titration with standard liquid of barium perchlorate.

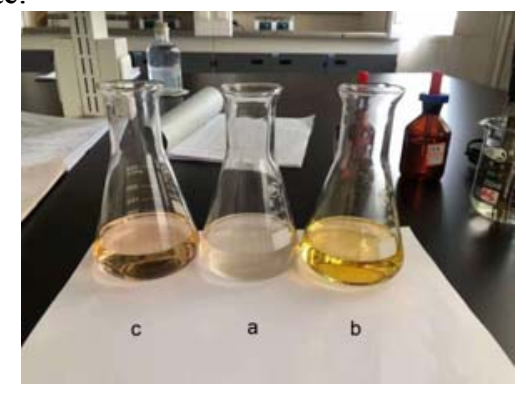

Fig.1. The change in color of a sample during titration.

\subsection{Test conditions}

All units in this study were tested at the measuring point of chimney entrance, see Fig.2. During the test period, the load of the units was above $75 \%$, and the maximum fluctuation range was not more than 5\%. Moreover, denitration, dust removal and desulfurization systems were in normal and stable operation. Table 2 shows the coal quality of each unit 
during the test period. The types of coal burned by each unit were extra-low sulfur coal, low-sulfur coal, low-medium sulfur coal and medium-high sulfur coal.

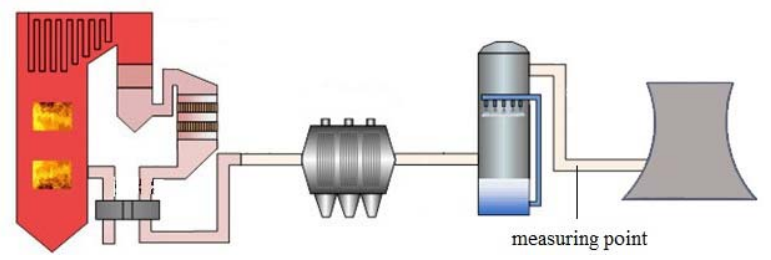

Fig.2. Schematic diagram of measuring point.

Table 2. Coal quality throughout the testing period.

\begin{tabular}{|c|c|c|c|c|}
\hline Unit & $\begin{array}{c}\text { Total moisture as } \\
\text { received basis / \% }\end{array}$ & $\begin{array}{c}\text { Ash content as } \\
\text { received basis / \% }\end{array}$ & $\begin{array}{c}\text { Sulfur content as } \\
\text { received basis } / \%\end{array}$ & $\begin{array}{c}\text { Volatile content as } \\
\text { dry ash-free basis } \\
/ \%\end{array}$ \\
\hline Unit A & $0.73^{*}$ & 44.68 & 1.02 & 17.28 \\
\hline Unit B & 16.0 & 25.98 & 0.45 & 38.66 \\
\hline Unit C & 15.4 & 27.51 & 0.40 & 39.1 \\
\hline Unit D & 21.9 & 16.97 & 0.48 & 36.92 \\
\hline Unit E & $1.69^{*}$ & 45.31 & 2.17 & 36.06 \\
\hline Unit F & 22.15 & 21.21 & 1.05 & 52.36 \\
\hline Unit G & $2.76^{*}$ & 30.53 & 0.42 & 25.55 \\
\hline
\end{tabular}

Note: ${ }^{*}$ is the air-dried moisture.

\section{Results and discussion}

Table 3. Testing results of $\mathrm{SO}_{3}$ emission concentration.

\begin{tabular}{|c|c|c|}
\hline Unit & $\begin{array}{c}\mathrm{SO}_{3} \text { emission } \\
\text { concentration/ } \\
\left(\mathrm{mg} / \mathrm{m}^{3}\right)\end{array}$ & $\begin{array}{c}\text { Sulfur } \\
\text { content as } \\
\text { received } \\
\text { basis } / \%\end{array}$ \\
\hline Unit A & 2.04 & 1.02 \\
\hline Unit B & 0.74 & 0.45 \\
\hline Unit C & 0.63 & 0.40 \\
\hline Unit D & 0.77 & 0.48 \\
\hline Unit E & 2.03 & 2.17 \\
\hline Unit F & 0.43 & 1.05 \\
\hline Unit G & 0.36 & 0.42 \\
\hline
\end{tabular}

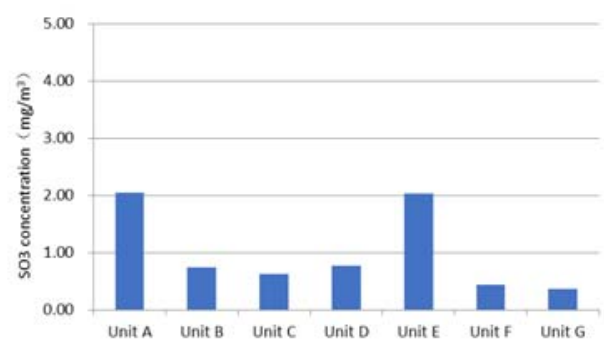

Fig.3. Comparison of $\mathrm{SO}_{3}$ emission concentration of each unit.

Table 3 and Fig. 2 show the measured $\mathrm{SO}_{3}$ emission concentration of each unit, which that the data at each sampling point are the average of three measurements and all test results have been converted to $6 \% \mathrm{O}_{2}$.As can be seen, the $\mathrm{SO}_{3}$ emission concentration of all units ranges from 0.36 to $2.04 \mathrm{mg} / \mathrm{m}^{3}$, which well below the emission limit of $6 \mathrm{mg} / \mathrm{m}^{3}$ proposed by 14 states in US and the emission limit of $5 \mathrm{mg} / \mathrm{m}^{3}$ required by individual cities in China (such as Hangzhou and Hengshui).

The $\mathrm{SO}_{3}$ emission concentration of unit $\mathrm{A}$ and unit $\mathrm{E}$ is the highest, because the sulfur content of the coal is higher. The sulfur content of unit A is $1.02 \%$ (low-medium sulfur coal), and that of unit $\mathrm{E}$ is $2.17 \%$ (medium-high sulfur coal), with a large difference, while the $\mathrm{SO}_{3}$ emission concentration of is close to each other. There are two reasons for this result. First of all, unit A adopts SCR denitration, which generates more $\mathrm{SO}_{3}$ than the 
SNCR denitration of unit E; Secondly, unit A adopts single-tower single-cycle WFGD, while unit $\mathrm{E}$ adopts double-tower double-cycle WFGD, the latter has higher $\mathrm{SO}_{3}$ removal efficiency [5].

The sulfur content of of unit $\mathrm{F}$ is similar to that of unit $\mathrm{A}$, but the $\mathrm{SO}_{3}$ emission concentration of unit $\mathrm{F}$ is only $0.43 \mathrm{mg} / \mathrm{m}^{3}$, which is attributed to the difference in pollutant treatment facilities. The main difference is that unit $F$ adopts LLTESP and WESP. According to the literature, LLTESP can significantly reduce the specific resistance of fly ash, improve the critical coronal voltage and breakdown voltage, increase the particle size of fly ash at the entrance of the precipitator, and reduce the flow rate and volume of flue gas, so that the $\mathrm{SO}_{3}$ removal rate can reach more than $90 \%$. The removal rate of $\mathrm{SO}_{3}$ by WESP can also reach $80 \%$. The author further tested the $\mathrm{SO}_{3}$ concentration at the desulfurization inlet of unit $\mathrm{F}$, and the result is $1.63 \mathrm{mg} / \mathrm{m}^{3}$. The removal rate of $\mathrm{SO}_{3}$ by WFGD + WESP of the unit $\mathrm{F}$ is $73.91 \%$.

According to the above analysis, for low-medium sulfur coal and below coal quality, the $\mathrm{SO}_{3}$ emission concentration of can be controlled within relatively low range by using the existing ultra-low emission technology, and there is no need to add $\mathrm{SO}_{3}$ removal facilities. For middle-high sulfur coal, when SNCR denitration is adopted, because the production of $\mathrm{SO}_{3}$ is low, the emission concentration is less than $5 \mathrm{mg} / \mathrm{m}^{3}$. Because the coal quality is good in the western region of Inner Mongolia, the data of burning high-sulfur coal is lack. Subsequent research will be carried out on units burning high-sulfur coal in southwest China.

\section{Conclusion}

(1) The $\mathrm{SO}_{3}$ emission concentration of all units ranges from 0.36 to $2.04 \mathrm{mg} / \mathrm{m}^{3}$, much lower than $5 \mathrm{mg} / \mathrm{m}^{3}$, so there is no need to add $\mathrm{SO}_{3}$ removal facilities.

(2) With the same sulfur content in the coal, the $\mathrm{SO}_{3}$ emission concentration of the unit using LLTESP and WESP is lower, and the $\mathrm{SO}_{3}$ removal efficiency of WFGD + WESP is $73.91 \%$.

(3) For units burning medium-high sulfur coal, when SNCR + ESP + double cycle and double tower WFGD technology route is adopted, the $\mathrm{SO}_{3}$ emission concentration can also be controlled to be lower.

(4) In the future, research should be carried out on units burning high sulfur coal.

\section{Acknowledgements}

This work is supported by the Natural Science Foundation of Inner Mongolia autonomous Region (No. 2019BS05023) and the Self-funded Project of Inner Mongolia Electric Power Science \& Research Institute (2019-ZC-01).

\section{References}

1. L. Tang, J. Qu, Z. Mi, X. Bo, X. Chang, L. Anadon. Nat. Energy, 4, 929 (2019)

2. F. Zhu, Z. Sun, Z Shen. Electric Power, 52, 1 (2019)

3. W. Zuo, X. Zhang, Y. Li, C. Zhao, Y. Dong. Fuel Process. Technol., 206, 106461 (2020)

4. Y. Zhang, C. Zheng, F. Hu, H. Zhao, S. Liu. Z. Yang, Y. Zhu, X. Gao. Environ. Sci. Pollut. Res., 27, 4746 (2020)

5. D. Pan, L. Yang, H. Wu, R. Huang, Y. Zhang. J. Chem. Technol. Biot., 92, 598(2016) 